УДК 338.2

\title{
ПРОЕКТНОЕ УПРАВЛЕНИЕ РАЗВИТИЕМ МАЛОГО И СРЕДНЕГО ПРЕДПРИНИМАТЕЛЬСТВА В САМАРСКОЙ ОБЛАСТИ
}

\author{
Болдырева Олеся Анатольевна \\ Лебедева Ольга Андреевна \\ студенты
}

Научный руководитель: Болгова Елена Владимировна

к.э.н., доцент

ФГБОУ ВО «Самарский государственный экономический университет»

Аннотация: Уровень развития малого и среднего предпринимательства в различных регионах Российской Федерации значительно отличается, это зависит от множества факторов, так Самарская область отличается достаточно высоким развитием малого и среднего бизнеса. В статье рассмотрены основные показатели деятельности субъектов малого предпринимательства на территории Самарской области по видам экономической деятельности за 2019 г., при этом выявлен явный перевес в сторону оптовой и розничной торговли.

Ключевые слова: экономика, предпринимательство, малый бизнес, государственное регулирование, эффективность, поддержка малого предпринимательства.

\section{PROJECT MANAGEMENT FOR THE DEVELOPMENT OF SMALL AND MEDIUM-SIZED BUSINESSES IN THE SAMARA REGION}

\author{
Boldyreva Olesya Anatolyevna \\ Lebedeva Olga Andreevna \\ Scientific supervisor: Bolgova Elena Vladimirovna
}

\begin{abstract}
The level of development of small and medium-sized businesses in different regions of the Russian Federation differs significantly, it depends on many factors, so the Samara region is characterized by a fairly high development of small and medium-sized businesses. The article considers the main performance indicators of small businesses in the Samara region by type of economic activity for




\section{МОЛОДЕЖНАЯ НАУКА КАК ФАКТОР И РЕСУРС

2019, while revealing a clear advantage in the direction of wholesale and retail trade.

Key words: economy, entrepreneurship, small business, state regulation, efficiency, support of small business.

Малый бизнес во всем цивилизованном мире играет не последнюю роль в развитии рыночной экономики. Одной из особенностей развития малого предпринимательства является его возможность обеспечить достаточному количеству людей наличие рабочих мест, достойный доход работникам и, как следствие, сформировать средний класс. В развитых станах (Америке, Японии, европейских странах и т.д.) около половины трудоспособного населения занято в малом бизнесе. Немаловажной особенностью малого предпринимательства выступает его способность к инновациям, оно может стать толчком для зарождения и дальнейшего развития эффективных проектов, зарождения крупных компаний с высокотехнологичной продукцией. Возможность открыть свой бизнес дает возможность простому населению реализовать свои предпринимательские способности, совместить их с имеющимся творческим потенциалом, нестандартным мышлением, что позволяет рассматривать малый бизнес как институт рыночной конкурентной экономики.

Малый бизнес имеет ряд преимуществ перед крупным бизнесом, а именно: возможность начала бизнеса с меньшим стартовым капиталом; объединение функций собственности и управления; он довольно гибок, т.е. гораздо быстрее откликается на внешние изменения, у него высокая степень адаптации к потребностям клиентов; направленность на потребности конкретного региона, территории. Несмотря на указанные преимущества, малому предприятию объективно трудно конкурировать с крупными компаниями, в связи с этим со стороны государства разрабатываются и внедряются в жизнь программы поддержки и развития субъектов малого предпринимательства.

Тем не менее, необходимо отметить несовершенство действующей государственной политики в данном направлении, об этом явно свидетельствует тот факт, что на долю малого предпринимательства в России в объеме ВВП в 2019 г. пришлось только 26,3\%.

Уровень развития малого предпринимательства в различных регионах Российской Федерации значительно отличается, это зависит от множества 
факторов: экономических, социальных, политических и др. В частности, Самарская область отличается достаточно высоким развитием малого и среднего предпринимательства, оно выступает неотъемлемой частью экономики региона, оказывающей влияние на ее состояние и развитие. Обратим внимание на развитие субъектов малого предпринимательства, без учета среднего бизнеса и микропредприятий. Так, по состоянию на конец 2019 г. на территории Самарской области осуществляли свою деятельность 6543 субъекта малого предпринимательства (без учета микропредприятий). В 2019 г. на малых предприятиях число замещенных рабочих мест работниками списочного состава, внешними совместителями и работавшими по договорам гражданско-правового характера составило 195,1 тыс. Оборот субъектов малого предпринимательства в отчетном году составил 880904 млн руб[6].

Государственная поддержка субъектов малого и среднего бизнеса входит в область деятельности органов государственной власти Российской Федерации, органов государственной власти субъектов Российской Федерации, органов местного самоуправления, а также различных организаций, составляющих инфраструктуру поддержки субъектов малого и среднего предпринимательства, осуществляющих исполнение различных федеральных, региональных и местных государственных программ.

Среди мер государственной поддержки малого бизнеса целесообразно также сказать о необходимости со стороны государства активизировать участие субъектов малого бизнеса в государственных и муниципальных закупках, так как именно государственный заказ может выступать гарантированным источником финансирования и одной из антикризисных мер в современных экономических условиях. Для этого должны быть разработаны четкие механизмы привлечения субъектов малого бизнеса в качестве соисполнителей у крупных исполнителей государственных и муниципальных контрактов, необходимо осуществлять квотирование части государственного и муниципального заказа для малого предпринимательства. Система государственной поддержки малого бизнеса, генерированная на определенной территории, включает в себя:

- соответствующие нормативно-правовые акты;

-совокупность государственных институциональных структур, ответственных за развитие малого предпринимательства, регулирующих данную сферу и осуществляющих управление инфраструктурой еe поддержки; 
- государственную инфраструктуру, состоящую как из некоммерческих, так и коммерческих организаций, деятельность которых осуществляется по инициативе государства и направлена на развитие малого предпринимательства.

На территории Самарского региона работают следующие организации, составляющие инфраструктуру поддержки субъектов малого и среднего предпринимательства:

- Фонд развития бизнеса Самарской области;

- Центр поддержки предпринимательства;

- Центр координации поддержки экспорта Самарской области;

- Фонд микрофинансирования Самарской области.

В 2018 г. был создан Региональный инжиниринговый центр, в сфере деятельности которого оказание комплекса услуг субъектам малого и среднего предпринимательства, направленных на содействие технической и технологической модернизации предприятий малого и среднего предпринимательства. Данный центр вошел в состав Фонда развития бизнеса Самарской области. На территории Самарской области функционируют центры молодежного инновационного творчества, их появление обусловлено возрастающей в последние годы тенденции повышения инновационной активности предпринимательских структур, в том числе и представителей малого бизнеса.

В настоящее время как в целом по стране, так в Самарской области реализуется ряд программ поддержки малого и среднего предпринимательства.

Действует Программа льготного кредитования субъектов малого и среднего предпринимательства, реализуемая Министерством экономического развития Российской Федерации, которая ставит целью создание механизма поддержки субъектов малого и среднего предпринимательства путем субсидирования банкам недополученных доходов по льготным кредитам, предоставленным субъектам малого и среднего предпринимательства, выданным на цели приобретения оборудования, машин, транспортных средств, для пополнения оборотного капитала, а также для запуска новых, в том числе инновационных, проектов.

\section{Список литературы}

1. Адаменко А.А., Петров Д.В. Действующие льготы для субъектов малого бизнеса // Вестник Академии знаний. 2019. № 30(1). С. 194-198. 
2. Алексеева Н.А. Препятствия развитию малого бизнеса в регионе // Вестник Ивановского государственного университета. Серия: Экономика. 2014. № 2(22). C. 30.

3. Гнатюк А.Н. Основные подходы к изучению малого бизнеса как субъекта адаптации // Гуманитарные, социально-экономические и общественные науки. 2017. № 4. С. 21-25.

4. Гонежук М.К. Сравнительный анализ роли и места малого бизнеса в регионе // Естественно-гуманитарные исследования. 2019. № 26(4). С. 71-80.

5. Дивиченко О.И. Факторы развития малого предпринимательства в регионе в социологическом измерении // Наука. Общество. Государство. 2017. № 5-2(18). C. 137-141.

6. Кремин А.Е. Методический подход к оценке влияния малого бизнеса на экономику региона // Экономика и менеджмент систем управления. 2018. № 2(28). C. 21-28.

7. Латыпов Р.Т., Резниченко Д.В. К вопросу о конкурентоспособности малого и среднего предпринимательства в условиях рыночной экономики (на примере Российской Федерации и мировой практики) // Вестник Академии знаний. 2018. № 2(25). С. 148-153.

8. Мандрова А.А. Концептуальный подход к оптимизации государственной поддержки малого и среднего бизнеса в аграрной сфере // Вестник Тверского государственного университета. Серия: Экономика и управление. 2019. № 1. С. 175-183.

9. Папова, Л.В., Миронов О.А. Экономические санкции против России: вызовы и угрозы // Информационное обеспечение эффективного управления деятельностью экономических субъектов. Материалы VI международной научной конференции. Краснодар, 9-11 дек. 2015 / Сост. Ю.И. Сигидов, Е.В. Мартыненко, В.В. Башкатов. Майкоп: Изд-во «Магарин Олег Григорьевич», 2016. С. $544-549$.

10. Петров Д.В., Хорольская Т.Е. Малое предпринимательство России: современное состояние и перспективы развития // Естественно-гуманитарные исследования. 2020. № 2 (28). С. 215-219. DOI: 10.24411/2309-4788-202010104

11. Пушная Д.В. Роль малого бизнеса в развитии экономики региона (на примере северо-кавказского федерального округа) // Управление экономическими системами: электронный научный журнал. 2015. № 7(79). C. 23. 